\title{
Produce Safety and the Potential for Foodborne Disease: A Public Health Analysis
}

\author{
Sarah Delea ${ }^{1}$ \\ Fleishman-Hillard Inc., 2405 Grand Boulevard, \#700, Kansas City, MO 64108-2522
}

\begin{abstract}
Considering that diet is responsible for $65 \%$ of all cancers, the most important public health advice for Americans today is to increase consumption of fruits and vegetables to reduce risk of cancer and chronic disease. An abundance of research over the last decade has shown that a low-fat diet, high in fruits and vegetables, protects against many cancers and lowers the occurrence of coronary heart disease (Kennedy et al., 1996; Kushi et al., 1995; National Research Council, 1989).
\end{abstract}

Government and independent nutrition and health authorities, including the National Institutes of Health (NIH), the National Cancer Institute (NCI), the U.S. Food and Drug Administration (FDA), the U.S. Centers for Disease Control and Prevention (CDC), and the American Dietetic Association (ADA), agree that Americans should

Received for publication 7 Feb. 2000. Accepted for publication 8 June 2000. The cost of publishing this paper was defrayed in part by the payment of page charges. Under postal regulations, this paper therefore must be hereby marked advertisement solely to indicate this fact.

${ }^{1}$ E-mail address: swdelea@msn.com increase consumption of fruits and vegetables to five servings a day (Kennedy et al., 1996; Kushi et al., 1995).

To further emphasize the importance produce has in maintaining good public health, the U.S. Dept. of Health and Human Services (HHS) and the U.S. Dept. of Agriculture (USDA) urged Americans to consume between five and nine servings of fruits and vegetables in the U.S. Dietary Guidelines to Healthy People 2000. Additionally, cooperative public health efforts, such as the "5-A-Day For Better Health" program supported by HHS and NCI, are aimed at helping consumers reach the goals set out in the Dietary Guidelines of eating five serving of fruits and vegetables daily by the year 2000 (Kennedy et al., 1996; National Research Council, 1989).

But against this backdrop of overwhelming public health advice, recent reports of occasional outbreaks of foodborne disease associated with produce have raised questions about the potential of produce to cause gastrointestinal illnesses, threatening to overshadow the important dietary and medical role fruits and vegetables play in ensuring good health.

While microorganisms found on fruits and vegetables have been 
associated with foodborne outbreaks, research shows that these outbreaks have been isolated to a few select commodities, are usually due to cross-contamination, and do not a signal a larger-scale problem (Bean et al., 1990, 1996; Madden, 1992).

In fact, an analysis of overall incidents of foodborne disease outbreaks tracked by the CDC confirms that fresh produce is a rare contributor to such illness. Since 1986, 3277 foodborne disease outbreaks have been reported. Of those, fresh produce was linked to only 21 outbreaks, 10 of which were the result of cross-contamination during food preparation (Bean et al., 1990, 1996; Beuchat, 1995; Hedberg et al., 1994). Likewise, $97 \%$ of traceable foodborne disease outbreaks result from improper handling and cross-contamination (Bean et al., 1990, 1996).

Because fresh fruits and vegetables are such an important part of the diet, the produce industry takes seriously its responsibility to minimize the potential for contamination, and deals with public health officials openly and directly if and when contamination occurs.

The purpose of this paper is to review the current scientific research on outbreaks associated with produce, provide an analysis of produce and its potential to contribute to foodborne disease, and highlight actions the industry is taking to address any concerns.

\section{PRODUCE UNDER THE MICROSCOPE}

Fresh fruits and vegetables are raw agricultural products grown in the natural environment. Therefore, produce should be expected to carry a wide variety of microorganisms, including some pathogens at very low levels. Taking that into account, fresh produce is an extraordinarily safe and nutritious product.

When an outbreak can be associated with a particular food product, produce is rarely the culprit. Most fruits and vegetables possess a barrier that prevents microbes from entering and subsequently growing in the commodity's interior (Madden, 1992). Though recent outbreaks associated with select commodities have sparked more research in investigating the potential of microorganisms to survive and proliferate on fresh produce (Abdul-Raouf et al., 1993; Del Rosario and Beuchat, 1995), the major reason for increases in reported outbreaks is the increase in consumption of fresh produce (Bean et al., 1990, 1996; Madden, 1992).

The CDC reports that outbreaks of foodborne disease epidemiologically linked to produce averaged five per year from 1983 to 1992 (Madden, 1992). Note, however, that the CDC did not differentiate between fresh and processed fruits and vegetables when collecting and tabulating data. So, when examining outbreaks traceable to fruits and vegetables from 1983 to 1992, nearly one-third were due to Clostridium botulinum consumed in improperly canned products (Bean et al., 1990, 1996; Madden, 1992).

Some researchers theorize that the increased intake of fresh fruits and vegetables increases the potential for outbreaks of foodborne disease associated with these products (Hedberg et al., 1994). While consumption has increased over the last decade (U.S. Dept. of Agriculture, 1996a, 1996b), outbreak frequency has not followed the same trend, establishing that consumption patterns alone cannot predict patterns in outbreaks (Bean et al., 1990, 1996). Moreover, studies show consumption of red meat has decreased over the last 10 years, and yet the incidence of foodborne disease associated with this product has not diminished, but remained constant from 1988 to 1992 (Bean et al., 1996).

\section{POINT OF CONTAMINATION}

Where outbreaks of foodborne diseases associated with fresh produce have occurred, the majority of cases have involved a few select commodities and are primarily related to cross-contamination during food handling or preparation near the point of sale or in the home. Moreover, outbreaks associated with produce tend to occur on a seasonal basis, primarily during the warmer spring and summer months (Bean et al., 1990).

According to the CDC, $77 \%$ of all traceable outbreaks result from improper handling in food service establishments and $20 \%$ from improper handling in the home; only $3 \%$ originate from the source of the food product. In fact, CDC data from 1983 to 1992 confirm that the most common practices contributing to such outbreaks were improper holding and cooking temperatures, followed by the poor personal hygiene of food handlers. Food from an unsafe source was the least common cause of all outbreaks (Bean et al., 1990, 1996; Knabel, 1995).

While intense focus has turned to the microorganisms that may affect produce and cause illness, many of the incidents associated with produce are related to improper handling of product, such as poor sanitation or improper hygiene among food preparers (Beuchat, 1995; Hedberg et al., 1994; Knabel, 1995).

\section{CONTAMINATION DUE TO IMPROPER HANDLING, PREPARATION, AND CROSS-CONTAMINATION}

Mishandling, improper storing and holding temperatures, and cross-contamination with other hazardous raw products, such as meat and poultry, are the most common modes of pathogen contamination of produce (Bean et al., 1990, 1996; Beuchat, 1995; Knabel, 1995). For instance, a 1989 outbreak of Campylobacter in Missouri resulted from cross-contamination of melons (Cucumis melo L.) and pineapples [Ananas comosus (L.) Merr.] when a food preparer sliced poultry and fruit on the same surfaces (Bean et al., 1996).

According to the CDC's Surveillance of Foodborne Disease Outbreaks: 1988-92, a 1990 outbreak of Salmonella occurred when various items from a salad bar were contaminated by uncooked meat and poultry in a restaurant kitchen (Bean et al., 1996). Further illustrating the prevalence of cross-contamination, Dr. Larry Beuchat (1995), of the Univ. of Georgia, highlights Salmonella outbreaks associated with consumption of sliced melons obtained from salad bars in 1990 and 1991. Investigators in both cases concluded that contamination of the melons occurred when food handlers did not thoroughly wash the rind, thus contaminating the fruit during and after cutting. Storing the melons at high temperatures after cutting was also recognized as a causative factor (Beuchat, 1995).

In describing the 1991 outbreak of $S$. poona associated with cantaloupes (Cucumis melo L., Inodorus group) in a fruit salad, Hedberg et al. (1994) concluded that "cross-contamination of the fruit from the [unwashed] rind occurred" and that "extra handling required to prepare fruit salads and salad bars may have increased the potential for contaminating the fruit from the rind."

Because of these sporadic incidents, FDA recognized the critical need to educate food handlers on how to properly clean and handle cut melons, and implemented the following guidelines in the 1993 model Food Code: 1) wash and sanitize melon rinds, cutting utensils, and preparation surfaces in order to prevent cross-contamination before serving; 2) display cut melon at or below $7^{\circ} \mathrm{C}$ for no more than 4 hours; and 3) discard unsold products after 4 hours (Bean et al., 1996; Beuchat, 1995; Madden, 1992; Hedberg et al., 1994; U.S. Dept. of Health and Human Services, 1993).

FDA developed the model Food Code in 1993 to provide guidelines for state and local government to assure that food at retail is properly handled and displayed. While they are not federally mandated, the model Food Code provisions are designed to be consistent with federal food laws and regulations (U.S. Dept. of Health and Human Services, 1993).

Researchers have also documented incidents of Escherichia coli O157:H7 outbreaks associated with various types of lettuce (Lactuca sativa L.) and cut melons due to cross-contamination by food handlers. An outbreak in 1993, traced to an Oregon restaurant, was caused by consuming cantaloupe and other salad bar food items that were contaminated by meat products during preparation (Del Rosario and Beuchat, 1995; Feng, 1995).

In July 1995, an outbreak associated with leaf lettuce occurred in Montana. While the means of contamination were not determined, surface water used for irrigation, plus a grocery store's unsanitary lettuce handling methods, are considered the likely causative agents (K. Weschsmuth, personal communication). In September of that same year, researchers strongly suspected that an outbreak of $E$. coli O157:H7 linked to iceberg lettuce at a Boy Scout camp in Maine was the result of cross-contamination of the commodity with raw meat 
products during preparation. In Idaho during the same period, an outbreak associated with red cabbage (Brassica oleracea L., Capitata group) and romaine lettuce (L. sativa L. var. longifolia Lau.) was caused by restaurant food preparers who had improperly stored the commodities, as well as cross-contaminated them, with meat products (F. Weschmuth, personal communication).

\section{CONTAMINATION DUE TO POOR PERSONAL HYGIENE AND INFECTED HUMAN CONTACT}

Second to improper handling and cross-contamination, the most common means of transmitting microorganisms to a food item is poor personal hygiene of food preparers, including consumers at home.

In 1986, an outbreak was associated with the parasite Giardia lamblia in a fruit salad eaten at a family gathering. Upon investigation, researchers discovered that the woman who prepared the salad had an asymptomatic child in diapers, and successfully isolated the parasite in stool samples from the mother, child, and a pet rabbit (Bean et al., 1990). Researchers documented another outbreak of G. lamblia, associated with raw vegetables, caused by a contaminated food handler who was slicing the vegetables (Bean et al., 1996).

In 1988, an outbreak of hepatitis A among restaurant patrons in Kentucky was linked to consumption of commercially distributed iceberg lettuce. Investigators strongly suspect that the lettuce was contaminated by an ill food handler prior to distribution (Bean et al., 1996; Beuchat, 1995).

Further illustrating how poor hygiene can spark an outbreak of foodborne illness, Besser-Wiek et al. (1996) detailed an outbreak of foodborne diarrheal illness caused by Cryptosporidium parvum. In that case, 50 people attending a social event in Blue Earth County, Minn., became ill with acute gastroenteritis after eating salad that had been prepared by the owner of a licensed day-care home while she was overseeing her young charges. The woman told investigators that she had changed diapers shortly before making the salad. Besser-Wiek et al. (1996) concluded that, while the evidence remained largely circumstantial, the outbreak was more than likely linked to the woman changing the diaper and then not thoroughly washing her hands prior to preparing the salad.

\section{BEYOND U.S. BORDERS}

Some observers have speculated that imported produce may be less safe than domestically grown produce. However, the produce purchased from the street vendor in a developing country should not be confused with what is exported to the United States.

Fresh fruits and vegetables imported into the United States provide consumers year-round availability of fresh produce, as well as help offset the short domestic supplies between seasons. According to the USDA, the United States imports $20 \%$ of the fresh produce consumed domestically, of which a substantial quantity is grown and shipped from U.S.-owned or co-managed operations overseas, with production and handling adhering to U.S. standards. The fact that a product is grown outside the United States does not inherently mean it is less safe (FDA Consumer, 1997; U.S. Dept. of Agriculture, 1996a, 1996b).

Researchers have implied that imported products from Mexico, Central America, and South America may increase the incidence of foodborne disease outbreaks (Beuchat, 1995; Felix, 1997; Hedberg et al. 1994). However, imports from these regions are at the highest levels during the winter and fall months, whereas CDC data show that outbreaks associated with produce tend to occur during the spring and summer months (Bean et al., 1990, 1996). Health officials and researchers theorize that this is due to poor temperature control and improper storage after harvest.

Furthermore, quality in the United States and abroad drives the market, and many companies that export to the United States also export fresh produce to countries that have equally stringent quality standards, such as Japan and the European community. In order to meet worldwide demand for enhanced quality, exporters have invested resources in improving production, handling, and transportation technology to ensure that their products, across the board, meet the most restrictive quality standards (FDA Consumer, 1997; Tilton, 1996).

\section{INDUSTRY TAKING ACTION}

Even though foodborne illness is less likely to be associated with produce than with other food products, the industry has welcomed examination of its practices all along the chain, from fields to packing houses, and from distribution centers to retail and food service outlets.

The industry maintains an open dialogue with officials at FDA and CDC about how produce is grown, shipped, packed, and sold and has encouraged inspections of fields, and of harvesting and packing operations to evaluate practices. If a practice is identified as a potential source of contamination, industry representatives work with FDA and state health officials to reduce the potential of microbial hazards (Madden, 1992). For example, after outbreaks associated with melons, the industry took great strides in improving washing, handling, distribution, and storage of melons and implemented the Melon Quality Program (Madden, 1992; Maxwell et al., 1991; U.S. Dept. of Health and Human Services, 1993).

Domestically grown tomatoes were implicated in an outbreak of Salmonella in 1990 and again in 1993. Though no Salmonella species were isolated from the tomatoes, growers and packers supported research to minimize and prevent potential contamination (Bean et al., 1996; Zhuang et al., 1995). Zhuang et al. (1995) recommended that tomatoes be rinsed in a hyperchlorinated solution and that the water temperature for rinsing tomatoes be $10{ }^{\circ} \mathrm{C}$ warmer than the fruit temperature in order to avoid water uptake into the fruit core. Tests for Salmonella on tomatoes in 1994 and 1995 were negative, verifying that controlling water quality and temperature were effective in reducing contamination (Zhuang et al., 1995).

In July 1996, 27 cases of E. coli O157:H7 in Illinois and 18 cases in Connecticut were related to consumption of a mesclun leaf lettuce mix. While no E. coli $\mathrm{O} 157: \mathrm{H} 7$ was isolated in the mix, investigators publicly speculated that contamination of the various leaf lettuces used occurred prior to distribution (Illinois Dept. of Public Health, 1996). Even though researchers were unable to pinpoint the exact source of contamination, the lettuce industry worked proactively with state health officials and reexamined practices used to clean and store produce, including better sanitation of hydrocoolers and hydrovacs used to cool the produce (Tilton, 1996).

An investigation into a 1995 outbreak of Salmonella in Michigan led to the implication of alfalfa (Medicago sativa L.) sprouts, which may have been grown from contaminated seed. Currently, researchers are investigating ways to avoid seed contamination prior to sprout production, as well as the effectiveness of a hyperchlorinated water rinse for sprouts (K. Weschsmuth, personal communication).

After the Cyclospora outbreak in 1996, microbiologists and produce industry associations convened to help public health officials properly identify the source of the illness, as well as to develop quality control and quality assurance programs. Guatemalan raspberry $(R u$ bus sp. hybrids) producers worked closely with CDC and FDA to institute measures to prevent future contamination. While no Cyclospora has ever been isolated from raspberries, the CDC, FDA, and the Guatemalan grower organizations continue collaborative investigative efforts and have developed a Hazard Analysis Critical Control Points (HACCP)-like plan for raspberry production (Ackers, 1996; Jackson et al., 1997).

Additionally, other segments of the produce industry have taken steps proactively to ensure quality and safety. For example, the California Strawberry Commission implemented a Quality Assurance Program (QAP), which has won praise from the FDA, the California Dept. of Agriculture, and the California Dept. of Health Services. The QAP allows the strawberry (Fragaria $\times$ ananassa Duch.) industry to achieve the highest standard for field sanitation and worker safety (California Strawberry Commission, 1997).

\section{MINIMALLY PROCESSED AND FRESH-CUT PRODUCE}

For minimally processed fruits and vegetables, like fresh, nonpasteurized juice and fresh-cut produce, HACCP-type systems are in place and are recommended as the best approach to control patho- 
gens. This system identifies critical control points concerning biological, chemical, and physical hazards in the manufacturing process and establishes the means to control these hazards (Beuchat, 1995).

Considering that minimally processed products are packaged readyto-eat, the industry has embraced HACCP-type programs to implement the following controls: store raw, whole products at or below 34 to $40{ }^{\circ} \mathrm{C}$ prior to cutting; remove all foreign objects; wash produce before and after processing in sanitized water; run finished products through a metal detector; and store finished, processed products between 34 and $40{ }^{\circ} \mathrm{C}$ (Harris, 1997).

The key to preserving quality and ensuring safety is proper refrigeration; storage of fresh-cut products between 34 and $40^{\circ} \mathrm{C}$ is needed throughout the food distribution chain, from processor to grocery store to consumers' homes. This, in combination with the "breathable" plastic films used for packaging, helps reduce spoilage and pathogen growth, as well as maintain shelf life (Harris, 1997).

The produce industry takes seriously its responsibility to minimize the potential of contamination and is consistently improving its agricultural handling and processing practices. The industry has also moved forward to enhance and revise systems to better track products throughout the distribution chain in order to find the specific source of an outbreak quickly, rather than alarm consumers by implicating all products.

\section{GOOD INTENTIONS-BAD ADVICE}

While alerting consumers about potential outbreaks is important, public health officials must also base their announcements on sound, scientific data and provide the public with the most specific advice possible. Pressure from local constituents sometimes propels local health officials to act prematurely before data are conclusive, or to make incorrect, broad statements about entire commodities, causing the general public to be unnecessarily alarmed and an entire industry unduly damaged. Furthermore, public statements based on poor data can wrongly identify a food item, and lead consumers to avoid a safe, healthy one.

During the summer of 1996, an investigation into an illness caused by a microscopic parasite known as Cyclospora led a local Houston public health official to publicly and incorrectly assert that California strawberries were the source of the outbreak and to advise consumers not to eat them (Texas Dept. of Health, 1996). Subsequently, over 50 additional outbreaks of Cyclospora were reported in other states. After a lengthy and thorough investigation, CDC and other state public health epidemiologists concluded that Guatemalan raspberries-not strawberries-were the probable source of the illness (California Strawberry Commission, 1997; Colley, 1996; Felix, 1997; Jackson et al., 1997).

Based upon the incorrect statement from Texas, a bias was established against strawberries, prompting other state health officials to further incorrectly attribute the outbreak to strawberries, and compounding the difficulty of identifying the actual source. Ironically, food service outlets and grocery stores, following the incorrect advice of public health officials, substituted raspberries for strawberries; and consumers shifted from eating strawberries to raspberries, thus increasing their risk of exposure to Cyclospora (Colley, 1996; Felix, 1997).

As Dr. Michael Osterholm, Chief Epidemiologist, Minnesota State Dept. of Health stated, "I believe the Texas Health Dept. erred gravely in its effort and what it did.... It not only set us back in terms of credibility in the community, but it is also going to make it difficult in the future to do such [epidemiologic] studies" (Felix, 1997).

In addition to ensuring that they have correct data to support their claims, health officials also need to be precise and clarify the source of a foodborne illness when announcing an outbreak. For example, in Calhoun County, Mich., in Mar. 1997, health officials determined that a hepatitis A outbreak in two counties was associated with consumption of certain lots of frozen, sliced strawberries that were grown in Mexico and processed by one manufacturer in the spring of 1996. Yet, in their press statement, officials reported a "strawberry outbreak," omitting the word "frozen" (Calhoun County Dept. of Public Health,
1997). Subsequent media reports misled and frightened consumers away from perfectly safe, healthy, fresh strawberries, as well as frozen strawberries originating from other processors.

In other sectors of the food industry, media and health authorities are familiar with handling specific product recalls. Officials need to provide the same precision in addressing fruit and vegetable outbreaks tracked to specific suppliers.

Currently, no uniform national system exists in the United States for surveillance of outbreaks. Nor is there a system in place to assure the quality of individual state or local findings, which are crucial for CDC when investigating outbreaks, or guidelines on alerting the public. It would be helpful to consumers, industry, and epidemiologists if uniform standards were established to guide federal, state, and local health officials when implicating specific foods as the source of an outbreak based solely upon epidemiological data (Colley, 1996; Felix, 1997; Hedberg, 1996).

\section{THE COST TO PUBLIC HEALTH FROM MISPERCEPTIONS}

Health professionals nationwide agree that consumption of a diet rich in fruits and vegetables is one of the single most important steps consumers can take to improve their health and prevent heart disease, cancer, and other chronic diseases (Kushi et al., 1995; National Research Council, 1989). Nevertheless, when investigating an outbreak or reporting in the media, one can easily become overly fixated on minimal risks of illnesses associated with produce and lose sight of the major benefits to health provided by fresh fruits and vegetables. Consumption of fresh produce represents the most important factor in determining long-term prospects for healthy living, and is a basic principle of all federal nutrition and health policies from the U.S. Dietary Guidelines for Healthy People 2000 to NCI's 5-A-Day Program (Kennedy et al., 1996; Kushi et al., 1995; National Research Council, 1989).

Because it is infrequent, the occurrence of foodborne disease associated with produce is novel and makes news. Unfortunately, this can lead to public scares that put the safety of produce in question and result in reduced consumption of important, healthy foods. Adding to this negative health impact is the potential for public health officials to make well-intentioned, but incorrect and alarming, public statements that wrongly implicate foods (Calhoun County Dept. of Public Health, 1967; Felix, 1997; Texas Dept. of Health, 1996).

Furthermore, publicity about these infrequent outbreaks tends to exaggerate the actual incidents associated with produce. In the long term, this can have a greater negative impact on public health, causing consumers to lose confidence in fresh fruits and vegetables. Therefore, the minimal risks from microbial pathogens on produce must be balanced with the health benefits of these foods (Archer, 1996; Kushi et al., 1995).

\section{SUMMARY}

Per capita consumption of fresh fruits and vegetables has steadily risen over the last 20 years, with a public health goal set to increase consumption to five servings of fresh produce daily (Del Rosario and Beuchat, 1995). The most significant steps industry can take to ensure that consumers continue to include fruits and vegetables in their diets is to continue preventive measures to minimize potential microbial contamination of such produce.

Furthermore, education is critical to ensure that all parties within the food chain take steps to reduce contamination, from the field to the store to consumers. Considering that cross-contamination of produce is the most common cause of outbreaks, consumers and food preparers need to pay close attention to safe food handling.

At the same time, public health officials need to put outbreaks of foodborne disease associated with produce in proper context, and balance consumer communications with messages of public health benefits. Overall, the industry and the public health community must continue to work together to ensure that sound science and good judgment result in the best possible public health advice for consumers. 


\section{Literature Cited}

Abdul-Raouf, U.M., L.R. Beuchat, and M.S. Ammar. 1993. Survival and growth of Escherichia coli O157:H7 on salad vegetables. Appl. Environ. Microbiol. 59:1999-2006.

Ackers, M. 1996. Memorandum to Rodolfo Quezada, President, Commission of Berries, Guatemalan Association of Exporters of Non-Traditional Products.

Archer, D. 1996. Should all juices be pasteurized? U.S. Dept. Health Human Services, Food and Drug Admin. Natl. Advisory Comm. on Microbiological Criteria for Foods, Fresh Produce Subcommittee, Vol. 1, Mon. 16 Dec, Arlington, Va. [http://vm.cfsan.fda.gov/ lrd/1216fda.html]

Bean, N., J.S. Goulding, C. Lao, and F.J. Angulo. 1996. Surveillance for foodborne-disease outbreaks-United States, 1988-1992. Morbidity Mortality Weekly Rpt. 45:1-55.

Bean, N., P. Griffin, J.S. Goulding, and C.B. Ivey. 1990. Foodborne disease outbreaks, 5-year summary, 1983-1987. Morbidity Mortality Weekly Rpt. 39:15-23.

Besser-Wiek, J.W., J. Forfang, C.W. Hedberg, J.A. Korlath, M.T. Osterholm, C.R. Sterling, and L. Garcia. 1996. Foodborne outbreak of diarrheal illness associated with Cryptosporidium parvum. Minnesota. Morbidity Mortality Weekly Rpt. 45:783.

Beuchat, L.R. 1995. Pathogenic microorganisms associated with fresh produce. J. Food Protection. 59:204-216.

Calhoun County Department of Public Health. 1997. Health Alert.

California Strawberry Commission. 1997. Quality assurance program: Grower and shipper checklist. Watsonville, Calif.

Colley, D.G. 1996. Widespread foodborne cyclosporiasis outbreaks present major challenges. Emerg. Infect. Dis. 2:354-355.

Del Rosario, B.A. and L.R. Beuchat. 1995. Survival and growth of enterohemorrhagic Escherichia coli O157:H7 in cantaloupe and watermelon. J. Food Protection 58:105-107.

FDA Consumer. 1997. Safe handling of fruits and vegetables. 31: (March). [http://www.fda.gov/fdac/fdachtml.html]

Felix, C. 1997. National response team proposed for multi-state outbreaks. Food Protection Rpt. 13:2-3.

Felix, C. 1997. Tainted treatment water likely cause of Cyclospora organism. Food Protection Rpt. 13:7-8.

Feng, P. 1995. Escherichia coli serotype O157:H7: Novel vehicles of infection and emergence of phenotypic variants. Emerg. Infect. Dis. 1:47-52.
Harris, L. 1997. Reducing microbiological hazards, p. 68-71. In: The 1997 Produce Services Source Book..

Hedberg, C.W. 1996. Annotation: Why foodborne disease surveillance is critical to the safety of our food supply. Amer. J. Public Health Editorials 86:970.

Hedberg, C.W., K.L. MacDonald, and M.T. Osterholm. 1994. Changing epidemiology of food-borne disease: A Minnesota perspective. Clin. Infect. Dis. 18:671-672.

Illinois Department of Public Health. 1996. E. coli O157:H7 cluster linked to eating red leaf lettuce. 11 July, Press release [http://www.idph.stateil.us/ public/press96/eco.htm].

Jackson, G.J., J.E. Leclerc, J.W. Bier, and J.M. Madden. 1997. CyclosporaStill another new foodborne pathogen. Food Technol. 51:120.

Kennedy, E., L. Meyers, and W. Layden. 1996. The 1995 dietary guidelines for Americans: An overview. J. Amer. Dietetic Assn. 96:234-237.

Knabel, S.J. 1995. Scientific status summary foodborne illness: Role of home food handling practices. Food Technol. 49:119-131.

Kushi, L.H., E.B. Lenart, and W.C. Willet. 1995. Health implications of Mediterranean diets in light of contemporary knowledge. 1. Plant Food and Dairy Prod. Amer. J. Clinical Nutr. 61:1407S-1415S.

Madden, J.M. 1992. Microbial pathogens in fresh produce-The regulatory perspective. J. Food Protection 55:821-823.

Maxwell, P., R. Houck, D. Funk, J. Walzel, E. McCollough, and J. Snowdon. 1991. Melon Quality Program. Los Banos, Calif.

National Research Council. 1989. Diet and Health: Implications for reducing chronic disease risk. National Acad. Sci. Press, Washington, D.C.

Texas Dept. of Health. 1996. Investigation ties parasitic infections to fresh strawberries. New release 8 June [www.tdh.state.tx.us/news/b_news93.htm].

Tilton, L. 1996. Winter melons strengthen seasonal selection. Produce Business 80:57-59.

U.S. Dept. of Agriculture. 1996a. Fruit and tree nuts situation and outlook report. U.S. Dept. Agr. Commercial Agr. Div., Econ. Research Serv., No. FTS-278.

U.S. Dept. of Agriculture. 1996b. Vegetables and specialties situation and outlook. U.S. Dept. of Agr. Commercial Agr. Div. Econ. Res. Serv., No. Vegs-270.

U.S. Dept. of Health and Human Services. 1993. Food Code.

Zhuang, R.-Y., L.R. Beuchat, and F.J. Angulo. 1995. Fate of Salmonella montevideo on and in raw tomatoes as affected by temperature and treatment with chlorine. Appl. Environ. Microbiol. 61:2127-2131. 